https://doi.org/10.19195/0137-1169.39.2

JOANNA BŁASZCZAK

ORCID: 0000-0002-8332-2827

Uniwersytet Wrocławski, Poland

MARZENA ŻYGIS

ORCID: 0000-0002-2596-9171

Leibniz-Centre General Linguistics, Berlin, Germany

BETTINA BEINHOFF

ORCID: 0000-0003-0634-6611

Anglia Ruskin University, Cambridge, United Kingdom

\title{
What influences our attitudes? A survey study on attitudes of Polish university students towards German people*
}

\section{Introduction}

Germany and Poland are two neighbouring countries that have had very difficult relations in the past. The dreadful memories of the Second World War are still present in the post-war Polish generation and this bloodstained history has determined the negative attitude of many Poles towards German people. This attitude has begun to change in the last few decades, especially after the fall of the Berlin Wall in 1989. With Poland's accession to the EU in 2004 and with the elimination of border controls in 2007, it has become easier for Poles, especially the young, to move to Germany for study or work. Today the Polish population in Germany

\footnotetext{
* We are grateful to all our respondents for taking part in the questionnaire. This research has been partly supported by the Bundesministerium für Bildung und Forschung (BMBF, Germany), Grant Nr. 01UG1411 to Marzena Żygis and by the Ministry of Science and Higher Education (MNiSW, Poland) and the Deutscher Akademischer Austauschdienst (DAAD, Germany), Grant Nr. 57393118 to Joanna Błaszczak and Marzena Żygis.
} 
amounts to 758,380 (as of December 31,2017) and is the second largest community after the Turkish (Statistisches Bundesamt 2019). Increased mobility, various opportunities for cooperating with German schools and universities, the possibility of participating in school exchanges, cultural events or sporting competitions, various study programmes, all contribute to a change in the attitude of young Poles towards their German peers. German is also now one of the most popular foreign languages taught in Polish schools (Komisja Europejska/EACEA/Eurydice 2016).

The increased migration of young Poles to Germany and the high uptake of German as a foreign language at schools gives reason to assume that attitudes towards Germany may have changed. After all, language learning and active engagement with the target language culture are widely considered to promote intercultural understanding, especially when these are perceived as positive experiences by language learners (e.g. Block 2014). For this reason, it would seem reasonable to assume that a higher level of German language proficiency among Poles would positively influence their attitude towards Germany. But is that really the case? Is knowledge of the German language the only or most relevant factor? After all, learners may view learning a language purely as acquiring a new resource (Risager 2006). In the following we provide an overview of other factors that might influence attitudes towards Germany and the Germans in this context.

Attitudes are evaluative in nature and as such are often considered to be 'summary evaluations' (Bohner/Wänke 2002). Attitudes are learned and as they are highly influenced by social and cultural norms, they are typically acquired during the process of socialisation (Ajzen/Fishbein 1980). In her work on Polish-German stereotypes, Mihułka (2007) emphasises the family as an important influence on the development of stereotypes and attitudes in general, alongside the influence of the media and school - here especially history and German language lessons. Given that the family is the primary source for the socialisation of young children, the family is probably the most important factor in the development of attitudes and stereotypes at a young age. Mihułka singles out grandparents as a possible influence on the development of negative attitudes towards Germans due to their experiences of the Second World War and the post-war years. However, the relationship between Poles and Germans was also shaped in more recent history. Going back to the time when Poland shared a border with the German Democratic Republic (from 1949 to 1990) until Poland joined the Schengen area in 2007, negative stereotypes and even aggressive acts persisted on both sides, but especially on the German side, where Polish citizens continuously faced actions grounded in negative attitudes and disapproving stereotypes towards them (Mihułka 2008).

Considering the likelihood of persisting negative attitudes towards Germans and Germany among the Polish population, schools can play an important role to ameliorate such attitudes in older children. Especially language classes, school exchanges and cultural events are seen as venues for cultural learning and for increasing intercultural awareness in the learner. In this context, the work of Byram 
in the 1990s and early 2000s paved the way for an increasing inclusion of Intercultural Communicative Competence - and later Intercultural Citizenship - in language learning. In this approach, speakers of two or more languages are seen as mediators between cultures who can use the languages correctly, not only with regard to the language structures but also socially appropriate, depending on the communicative context (e.g. Byram/Golubeva 2012).

However, languages are often associated with specific national cultures which can in itself be problematic. This is not a problem inherent in Byram's approach, who was well aware of this: "The national culture will be seen as only one of the sets of cultural practices and beliefs to which an interlocutor subscribes - or is at least aware of as a framework for their actions" (Byram 1997:22). The interlocutor might see themselves as a member of a regional culture, a religious culture and a myriad of other cultures, but we argue that how this person is seen by others may be very different. In a sense, Blommaert's (2006) concept of inhabited identity (the identity the person claims) and ascribed identity (the identity given to the person by someone else) can be usefully applied here at the individual level. In intercultural communications, we may inhabit a certain identity (which is likely to include our nationality) but our interlocutor may still ascribe a different identity to us and, for example, may primarily view us in terms of how they see our national culture (and this interpretation of national culture may be very different from ours, possibly influenced by attitudes and stereotypes, as mentioned above). This process is entirely understandable because national identity is widely regarded as a key identity and it is typically used to position a person (Zappettini 2019). Thus, acquiring knowledge about aspects of the interlocutor's culture, the readiness to elicit such knowledge in interaction and reflecting and assessing one's knowledge in light of new information, seem to be essential skills in successful intercultural encounters. It is easy to see how language learning plays an important role in acquiring these skills and in acquiring appropriate knowledge about the cultures in which the language is typically spoken. This point is made by Mihułka (2007) with regard to German language teaching at schools in Poland, which has a central role in addressing prevailing stereotypes and can make students more culturally aware.

Studies outside of the Polish-German context have shown that language learning can be a way towards positive and meaningful interactions with the 'other' culture and a way to overcome stereotypes. For example, success in language learning is closely associated with positive attitudes towards the target language and its culture (e.g. Gardner/Lambert 1972, Masgoret/Gardner 2003). Indeed, attitudes towards the target language speakers and the target language community are seen as absolutely central in establishing the motivation to learn the language (e.g. Dörnyei $2003,2014)$, and ultimately positive attitudes are regarded as essential to achieving proficiency in the target language (Gardner 1985, 2001). Therefore, it would seem reasonable to assume that language learners who are successful in acquiring the target language hold positive attitudes towards the target language community. In 
addition, social networks - understood as the networks of individuals and groups with which we interact (Milroy 1987) - are considered to be especially important in determining how we evaluate other cultures. In particular, active engagement with the target community through social networks has been shown to positively affect attitudes and motivation (Isabelli-García 2006). This positive effect of interactions with members of the target language community has also been found in research on experiences by students studying abroad. Even short-term stays of between one month and three months have been shown to improve cultural skills significantly (Badstübner/Ecke 2009, Williams 2005). Thus, more opportunities to interact with members of the target community might lead to more positive attitudes.

At the same time, it is important to consider the particular context of contemporary Polish-German relations. For example, studies conducted in German-Polish border regions show that different approaches to economic development between the states affect perceptions of the other culture and may exacerbate or alleviate existing communication barriers. Krätke's study (1999) on economic development and integration in the German-Polish border region showed communication barriers between the neighbouring regions, exacerbated by a sense of reserve and distrust on both sides and the perception of high social distance between the neighbouring regions. Krätke explained this with - among other things - the aftermath of the Second World War, which saw a considerable population transfer which "made it difficult for populations on both sides of the border to identify with the region" (Krätke 1999:639). Note, however, that Krätke's study was conducted in the context of economic development before Poland became a member of the European Union. Since the border between Germany and Poland is now an inner European border, many of the obstacles described in Krätke (1999) are likely to have been mitigated. The study by Galasinska, Rollo and Meinhof (2002/2018) was conducted in the German-Polish town of Görlitz/Zgorzelec, which used to be entirely German but was divided into a German and a Polish part respectively following the treaty of Potsdam in 1945. Since 1989 free travel between Görlitz and Zgorzelec has been possible, and while inhabitants of the Polish part are frequent visitors to the German city of Görlitz, the people of Görlitz seem to visit Polish Zgorzelec only rarely. This is reflected in the generally positive attitudes of the Polish participants in this study towards the German inhabitants of Görlitz and the more negative expectations German visitors have when visiting Zgorzelec, indicating that frequent contact with the 'other' community has led to more positive attitudes. Crucially, Galasinska, Rollo and Meinhof found that old conflicts (especially referring to the horrible experiences of the Second World War) did not seem to be of much concern to their participants anymore; rather, they seemed to have been superseded by contemporary national ideologies (a finding that is central to what they term 'border paradox'). This latter finding directly contradicts those of Krätke (1999). Overall, the studies by Galasinska, Rollo and Meinhof (2002/2018) and Krätke (1999) indicate that attitudes are influenced by the specific context, which may lead to positive or negative outcomes. 
The above discussion suggests that (a) geographical closeness, (b) language proficiency, (c) frequency of contact and (d) quality of contact are all factors influencing attitudes towards members of a specific culture. However, no study has so far examined whether - and to what extent - these factors interact in influencing attitudes in a specific intercultural setting. The current situation of young educated Poles and their relationship with their German neighbours is ideal for studying changes in national ideologies and attitudes, for the reasons outlined earlier. By taking the above factors into consideration, we hope to obtain a more complex picture of the attitudes of young Poles who grew up at a time of rapid economic and cultural change, which may very well have affected widely-held attitudes towards Germany and its inhabitants.

Although to our knowledge there are no specific studies on attitudes of educated young people towards Germans, the statistics provided by the Polish Public Opinion Research Centre (CBOS) on the basis of regular national surveys give some initial insights into them. In these surveys, the respondents are asked to describe their attitudes towards other nationalities by using a 7-point scale ranging from sympathy (points +3 to +1 on the scale), via indifference (point 0 on the scale) to antipathy (points -1 to -3 on the scale), with the additional option of choosing the answer "I do not know". In the 2014 survey, Germans were in 15th position out of 34 nationalities, preceded by Czechs, Italians, Slovaks, Spaniards, Irish, French, Norwegians, Hungarians, English, Swiss, Swedes, Americans, Dutch, and Austrians (CBOS 2014). By 2017, Germans had edged up to 12th, but the number of nationalities included in this survey was only 25. Interestingly, a comparison of the results from 2014 and 2017 show a slight increase in sympathy (39\% in 2014 vs. $46 \%$ in 2017) and decrease in antipathy (30\% in 2014 vs. $22 \%$ in 2017) towards Germans (CBOS 2017). The middle position of Germans in these surveys corresponds to results obtained by Radomski and Szpyra (2014). The participants of their study completed a questionnaire in which they specified the degree of their sympathy for 11 different nationalities on a 10-point scale (10 = strong sympathy, $1=$ strong aversion). On the basis of the judgements obtained, Radomski and Szpyra (2014) classified the 11 nationalities into two groups: wellliked (above 5 points) and disliked (below 5 points). The score for Germans was 5.38. The nations with the highest score were the Americans and the British (over 7.80 points). The authors pointed out that the latter result might be attributed to the fact that the participants of their study were students of English who had a very positive attitude towards people whose language and culture they were studying.

In the present paper we investigate what educated young Poles (here: university students) think about Germany and whether their attitude towards Germany and German people is positive and/or similar among all young Poles.

The paper is organised as follows. In section 2 we present our research hypothesis and in section 3 we describe materials and methods used in the study. The results of the study are provided in section 4 and discussed from the perspective 
of cultural differences and similarities in section 5. Finally, section 6 summarises the main findings of the study.

\section{Research hypothesis}

In our study we put forward the hypothesis that the way people feel about Germany and Germans is determined by the following four factors: i) where they live (geography), ii) their level of German (language), iii) the frequency of contact they have with German people (contact), and iv) personal acquaintances with German people. More precisely, and based on the literature, we expect that the way our participants feel about Germany will be more positive i) the closer they live to the German border, ii) the better they know the German language, iii) the more often they visit Germany, and iv) the more German people they know personally.

In addition, we will have a closer look at differences among respondents from different places in Poland. We assume the existence of "inner-Polish" differences in feelings about Germany. More precisely, we expect the respondents from regions closer to Germany (Szczecin, Wrocław) to feel more positively about Germany than respondents from regions further away from the German border (Lublin). The goal of the present paper is to test these expectations.

\section{The present study: materials and methods}

In order to investigate our hypothesis, we conducted a questionnaire-based survey in three different Polish cities. The participants in our studies were young Poles, all of them students at the time of the study (2013) - that is, members of the third generation after the Second World War. The choice of cities was determined by their location. We took one city directly on the German-Polish border - Szczecin, which was German and named Stettin before the Second World War; one city in the south-western part of Poland, the capital of Lower Silesia - Wrocław, which at various times in history has been part of Prussia and Germany under its German name Breslau; and one city in the south eastern part of Poland, close to the Ukrainian border - Lublin.

The participants in the Szczecin survey were 36 Polish students of economics and electronics, aged $22-25$. In Wrocław the questionnaire was completed by 45 Polish students of English, Slavic and Romance philology and journalism, aged 21 29. In Lublin, 40 Polish students of English philology, aged between 20 and 25, took part in the survey. The questionnaire was conducted in paper form.

The questionnaire consisted of 52 questions (see Appendix). Altogether there were 5445 answers ( 52 questions $\times 121$ respondents). The questions covered personal information (e.g. age, gender, place of birth, German relatives and friends), 
contacts with Germans (e.g. frequency, reasons for interaction), language (e.g. proficiency in German, general attitudes to the German language), attitudes towards Germany and Germans (e.g. famous people, associations, comparison with Poland and Poles) and personal plans (e.g. living in Germany, a possible marriage with a German person, working or studying in Germany, German citizenship). Possible answers included binary YES - NO replies, multiple choice and open questions. The questionnaire took about 25-30 minutes to complete. Note that we will not discuss each of the 52 questions but only those which are directly relevant for testing our hypotheses.

\subsection{Data overview: general information}

Before providing the results concerning our hypotheses, we first give a general overview of the data by showing how our respondents answered some questions relevant for the present study.

First our data show that $71 \%$ of our respondents have visited Germany, while $29 \%$ have never been there. Furthermore, $41 \%$ of our respondents typically meet German people once every five years, $28 \%$ meet Germans at least once a year and $21 \%$ have never met any German person. Only $8 \%$ of our respondents have regular contact with German people.

Regarding contact with German people, we also asked if the respondents have German acquaintances, friends or relatives. The results show that $40 \%$ of our respondents have German acquaintances, $11 \%$ have German friends and 17\% German relatives.

Furthermore, we were interested in whether our respondents speak German. The results evince that more than half of them do speak German (56\%), but most of them identify their level as intermediate (26\%) or low (40\%). Only 5\% consider their level as high, and $2 \%$ as very high. Since $44 \%$ of the respondents do not speak German, the question arises as to whether they would be willing to learn it. Opinions appear to be evenly split: $36 \%$ of them would like to learn German and $36 \%$ would not ( $29 \%$ did not answer the question). We also asked our respondents if they like the German language and it turned out that most of the respondents do not $(74 \%)$. In fact, anecdotally, Poles often say that they do not like the way German sounds. Apparently, it sounds 'too harsh' for them.

We were also interested in whether our respondents could imagine living in Germany. As the results show, $36 \%$ of them could live in Germany and a slightly higher number (42\%) of our respondents can imagine living in Germany for a limited time, i.e. for study in particular.

We also dared to ask more personal questions: about $35 \%$ of our respondents can imagine having a German wife/husband, whereas $62 \%$ cannot; $25 \%$ would like to have German citizenship and $73 \%$ would not. In addition, our respondents were 
asked "What do you associate Germany with?" This was an open question and three responses could be given. The results show that $52 \%$ of our respondents associate Germany mainly with the Second World War, but also with the First World War or indeed both World Wars. The results are surprising insofar as they show that $48 \%$ do not associate Germany with the wars, which indicates that for this sample of participants, current national ideologies may be more relevant in establishing their neighbour's identity than 'old' conflicts (cf. earlier discussion of Galasinska/Rollo/ Meinhof 2002/2018). When our respondents think of Germany, they also think of the car industry (31\%), Oktoberfest (29\%), good motorways (21\%), order $(19 \%)$, accuracy $(16 \%)$, the Bundesliga (13\%), punctuality (7\%), and Bavaria $(6 \%)$.

Furthermore, among the best-known figures associated with Germany, Angela Merkel comes first (63\%), followed by Adolf Hitler (44\%), Johann Wolfgang von Goethe (15\%), Otto von Bismarck (12\%), Pope Benedict XVI (8\%) and Michael Schumacher (7\%).

Finally, 26\% of our respondents admire the German people, while $72 \%$ do not; $26 \%$ like the German people and $13 \%$ do not. For most of our respondents $(60 \%)$, it was difficult to say if they like the Germans.

The latter question was a starting point for investigating what factors might influence whether someone has a positive or negative attitude towards the German people. In particular, we examined how much this attitude depended on (i) frequency of contact with German people, (ii) whether they had German acquaintances, (iii) their level of German and (iv) where they lived.

\section{Results}

As stated above, in our questionnaire we asked directly about our respondents' attitude towards Germans with the question: "Do you like German people?". ${ }^{1}$ We hypothesised that the attitude towards Germany depends on the frequency of contact with German people. Figure 1 presents the results. Note that the relation between attitudes and other factors (place of residence, level of proficiency in German, frequency of visits to Germany, etc.) is statistically tested by means of the Pearson test, and if necessary, additionally evaluated by Fisher's test. All analyses were conducted in R environment software (version 3.0.2, R Development Core Team 2013).

Our results show that $25 \%$ of those respondents who like Germans visit Germany very often, $56 \%$ rarely and $16 \%$ never. However, from those who do not know if they like Germans, only 5\% have visited Germany very often, $49 \%$ rarely and $41 \%$ never. The dependence between the way one feels about Germany and the frequency of visits to Germany is significant $\left(\chi^{2}=12.9143, \mathrm{df}=4\right.$, Fisher's Test: p-value $<0.01)$.

${ }^{1}$ In Poland such a direct question is totally unproblematic. In everyday conversations people frankly admit which nationalities they like and which they do not. 
Do you like German people?

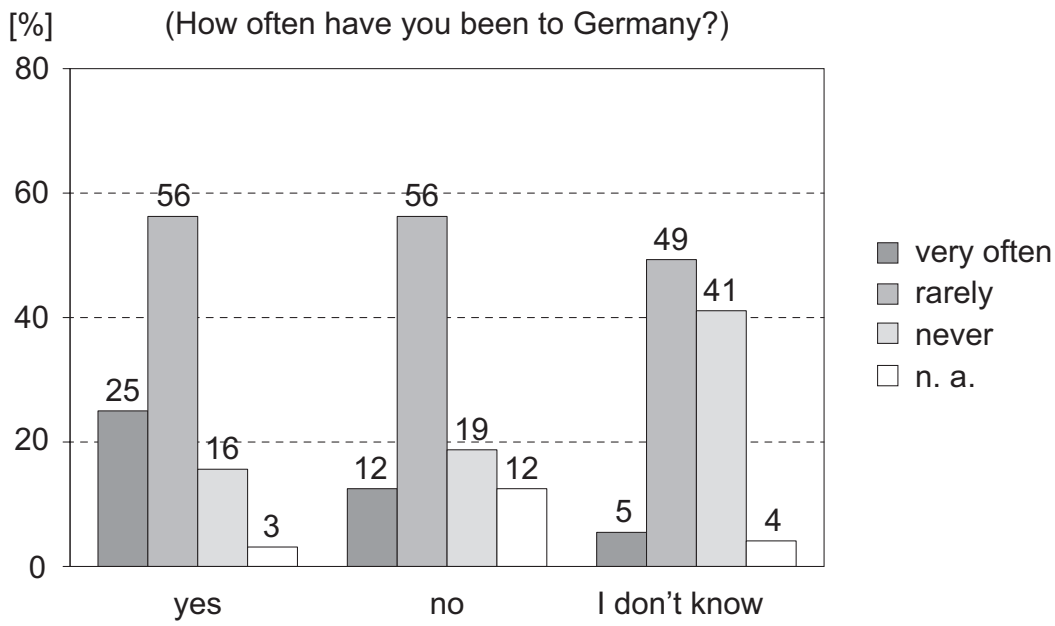

Figure 1: The percentage of answers depending on the frequency of visits to Germany

Do you like German people?

(Do you have German

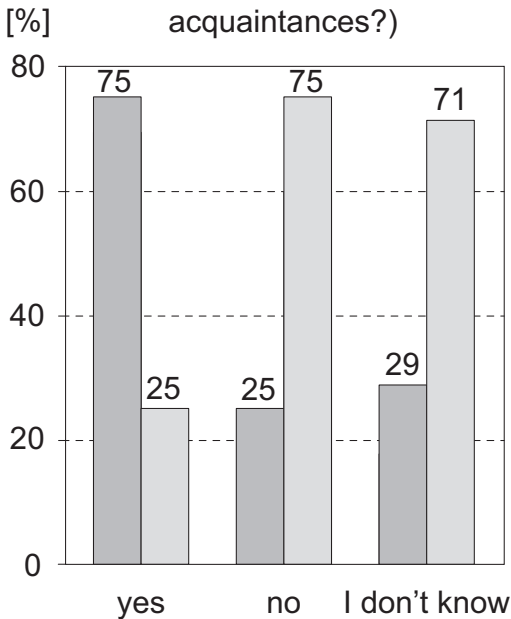

$\square$ acquaintances

$\square$ no acquaintances

Figure 2: The percentage of answers depending on German acquaintances

Furthermore, we hypothesised that the attitudes towards Germans might be dependent on whether one has German acquaintances. Figure 2 presents the results.

The interdependence between attitudes towards German people and the question of whether one has German acquaintances is highly significant $\left(\chi^{2}=21.572\right.$, $\mathrm{df}=2, \mathrm{p}<0001)$. Some $75 \%$ of those who like Germans have German acquaintances, while $25 \%$ of those with a positive attitude towards the German people do not have German acquaintances. The reverse picture emerges if we consider the 
Do you like German people?

[\%] (What is your level of German?)

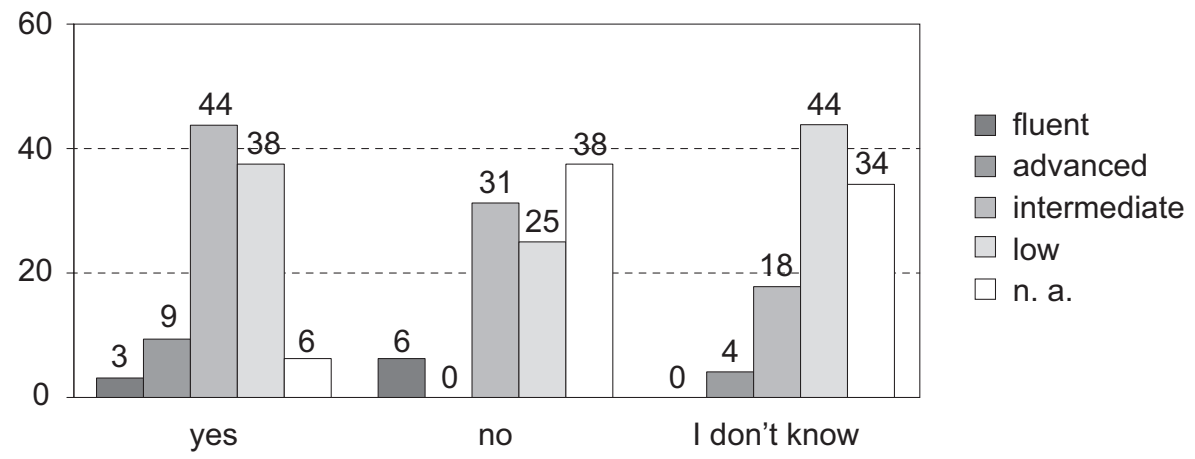

Figure 3: The percentage of answers depending on the level of German

results for those respondents who have a rather negative attitude towards German people: $75 \%$ of them do not have German acquaintances, while $25 \%$ do. Finally, among those who answered the question of whether they like German people with "I do not know", $71 \%$ do not have German acquaintances and 29\% do.

We also hypothesised that the level of knowledge of the German language influences attitudes towards Germans. This is because the knowledge of German enables access to German newspapers, German TV or enables one to make contacts with German people much easier. Figure 3 presents the results.

Our results show that there was no statistically significant dependence between the level of proficiency in German and the way our respondents perceive the German people. It must be stated, though, that the results show a statistical tendency towards such dependence $\left(\chi^{2}=10.3851, \mathrm{df}=6\right.$, Fisher's Test: $p$-value $=0.077)$. However, the lack of significant dependency might be influenced by the fact that the assessment of proficiency in German was based on a subjective judgement without any objective tests.

Finally, we were also interested in whether the place of residence influences the way Poles perceive Germans. This is illustrated in Figure 4 (left), which also shows how the answers were distributed in the cities investigated (Figure 4 (right)).

The results reveal that the attitude of our respondents towards German people depends on the place of residence $\left(\chi^{2}=10.6897, \mathrm{df}=4\right.$, Fisher's Test: $\mathrm{p}$-value $<0.05$; cf. Figure 4 (left)). The lowest number of positive answers was given by people living in Lublin (19\%), whereas the highest number of positive answers was obtained from people living in Wrocław (56\%). Interestingly, the highest number of negative answers ("I do not like German people") was also given in Wrocław (44\%), followed by Szczecin (38\%) and Lublin (19\%). Finally, the most answers of the "I don't know" type were obtained in Lublin (42\%), followed by Szczecin (30\%) and Wrocław $(27 \%)$. Thus, we can state that most of those respondents who do not have any opinion as to whether they like or dislike German people live far away from the border 


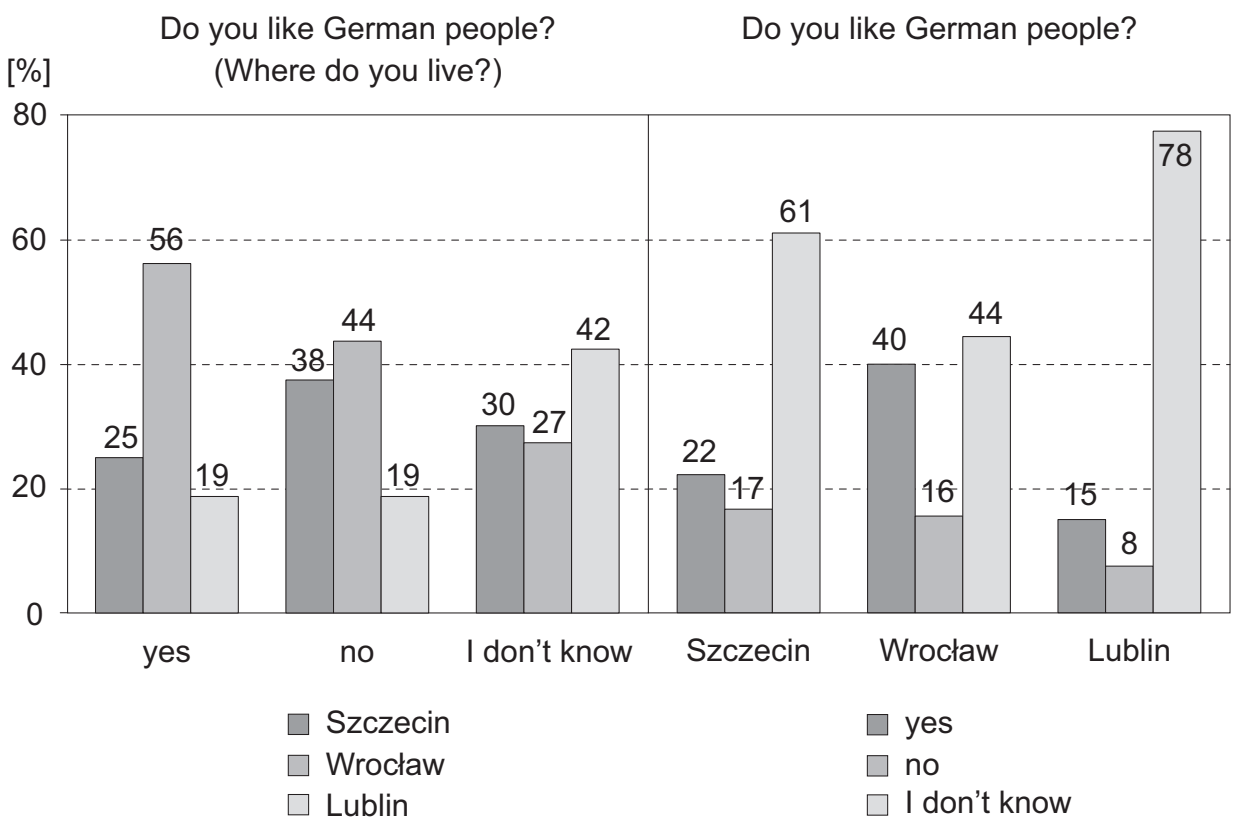

Figure 4: The percentage of answers depending on the place of residence

with Germany. However, we cannot state - on the basis of these results - that the closer people live to the border, the more positive their perceptions of Germans. This conclusion can be drawn by taking into consideration the data from Szczecin (which is directly on the German border). Despite this location, only $22 \%$ of our respondents from Szczecin like German people, while $17 \%$ of them do not like Germans. Moreover, $61 \%$ of our Szczecin respondents do not have any opinion on this issue. This encourages further investigation as the results may be due to specific regional and contextual factors (see Galasinska/Rollo/Meinhof 2002/2018, Krätke 1999).

The results presented above were based on $\chi^{2}$ tests, which investigate a dependence between two given variables. In the following, we propose an analysis in which all parameters can be included, namely, multinomial logistic analysis. The dependent variable is the Attitude of Polish respondents towards the German people with the following three sublevels: "I like German people", "I do not like German people", "It is difficult to say whether I like German people". The independent variables are Frequency of contact (very often, rarely, never), German acquaintances (yes, no), Level of German (fluent, advanced, intermediate, beginner), and Place of residence (Szczecin, Wrocław, Lublin). The reference level for the dependent variable was the answer "I do not like German people". Level 1 was the answer "I like them" and level 2 was "I don't know". 2 The results are presented in Table 1.

2 The final model used in our analysis was the following:

Model_final<- vglm (Attitude $\sim$ Frequency of contacts + German acquaintances + Place of residence, family $=$ multinomial () , data $=$ data $)$. 
Table 1: Multinomial analysis of the attitudes of Polish respondents towards the German people

\begin{tabular}{|l|c|c|c|c|}
\hline \multicolumn{1}{|c|}{ Ref: I do NOT like German people } & Estimate & Std. Error & z-value & p-value \\
\hline (Intercept):1 (“I like them”) & -1.47832 & 0.89075 & -1.65963 & $0.048^{*}$ \\
\hline (Intercept):2 (“I don't know”) & 0.50258 & 0.67232 & -0.74754 & n.s. \\
\hline Frequency of contacts: never:1 & 0.20423 & 1.34652 & 0.15167 & n.s. \\
\hline Frequency of contacts: never:2 & 1.96504 & 0.95573 & 2.05606 & $0.0198^{* *}$ \\
\hline Frequency of contacts: rarely:1 & 0.28790 & 1.04702 & 0.27498 & n.s. \\
\hline Frequency of contacts:rarely:2 & 1.33210 & 0.78108 & 1.70546 & $0.044^{*}$ \\
\hline German acquaintances: yes:1 & 2.17150 & 0.80209 & 2.70730 & $0.003^{* *}$ \\
\hline German acquaintances: yes:2 & 1.47451 & 0.54736 & 2.69384 & $0.003^{* *}$ \\
\hline Place of residence: Lublin:1 & -1.49457 & 1.15545 & -1.29350 & n.s. \\
\hline Place of residence: Lublin 2 & -0.64001 & 0.76975 & -0.83145 & n.s. \\
\hline Place of residence: Wrocław:1 & -0.61172 & 0.83235 & $\sim 0.73493$ & n.s. \\
\hline Place of residence: Wrocław:2 & -1.28144 & 0.62898 & -2.03732 & $0.02^{*}$ \\
\hline
\end{tabular}

In the following we concentrate only on those results that apply to the reference level "I don't like German people" (see Table 1), which show there are various dependencies which appear to be significant. Firstly, it is clear that all three parameters, i.e. Frequency of contacts, German acquaintances and Place of residence, contribute to the exploration of the dependent variable Attitude, albeit at different sublevels and to a different extent. Second, the results reveal some tendencies. For instance, people who have never met Germans are more likely to say, "I don't know" than "I don't like Germans" (79:8) in comparison to those who have met Germans very often (29:14). The same conclusion holds for those who have met German people very rarely. This is shown in Figure 5.

Furthermore, people who have German acquaintances are more likely to say "I like Germans" than "I don't like them" (49:8) in comparison to those who have no German acquaintances (11:17). In the same vein, people who have German acquaintances are more likely to say "It is difficult to say if I like Germans" than "I don't like them" (43:8) than those who have no German acquaintances (72:17), cf. Figure 6 (left). Finally, where people live has a significant effect on their attitude towards Germans. For instance, people from Wrocław are less likely to say "It is difficult to say if I like Germans" than "I don't like them" (44:16) in contrast to citizens of Szczecin (61:17), or even more clearly, in contrast to people from Lublin (78:8). This is shown in cf. Figure 6 (right).

In summary, the multinomial analysis confirms that proficiency in German is not significant, while other parameters such as frequency of contact with German people, German acquaintances and place of residence significantly contribute to attitudes towards Germans. 
Do you like German people?

[\%] (How often have you been to Germany?)

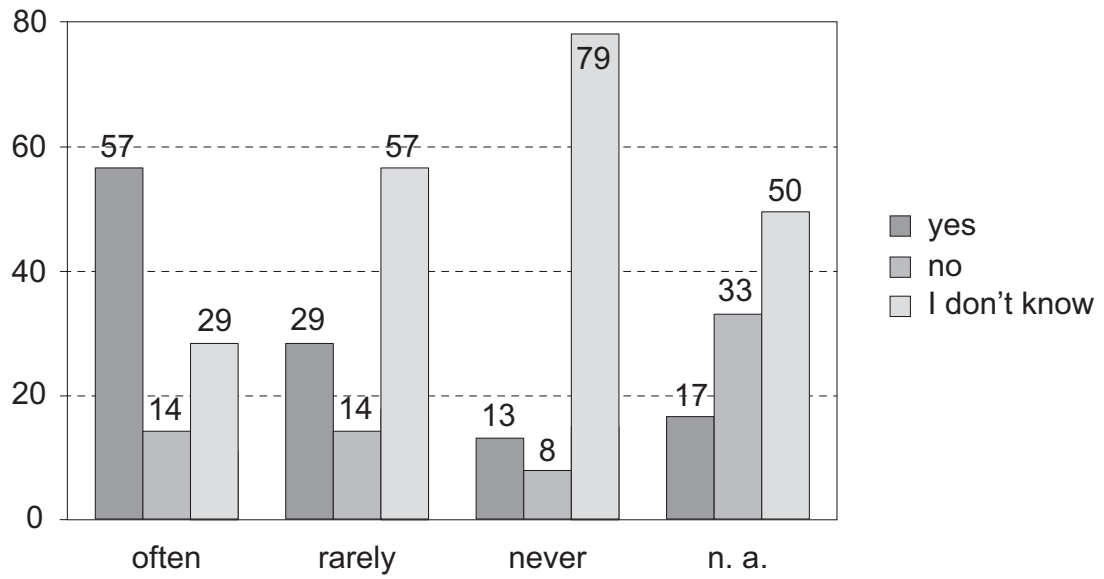

Figure 5: Frequency of visits to Germany

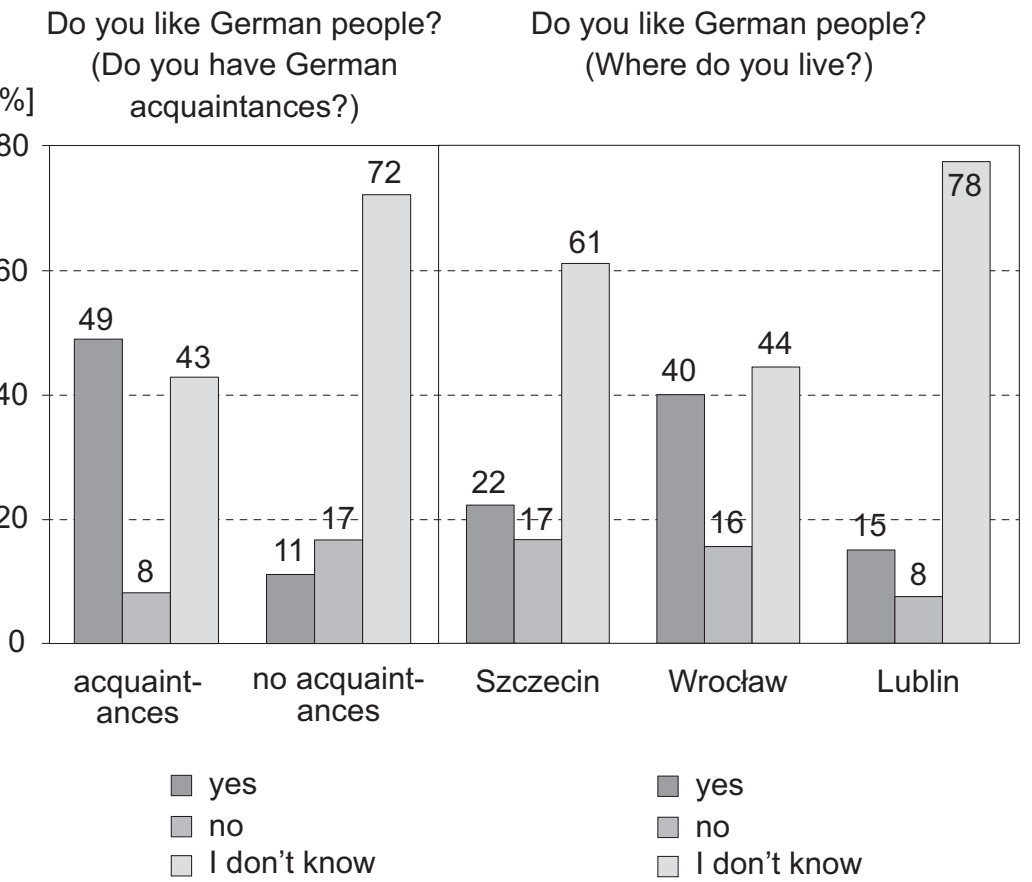

Figure 6: German acquaintances (left) and place of residence (right) 


\subsection{Data split by place of residence}

The significant contribution of place of residence inspired us to gain more insight into the data viewed from the perspective of people living in different cities. We were interested in whether there are inner-Polish differences regarding the factors discussed above.

Figure 7 presents the results obtained for the questions about frequency of visits to Germany and German acquaintances split according to place of residence. The results show that people living in Szczecin visit Germany most frequently (25\% are often in Germany), whereas most respondents from Lublin (60\%) have never been there. Regarding German acquaintances, there is a difference between respondents from Szczecin and Wrocław on the one hand, and Lublin on the other. Whereas about half of the former group have German acquaintances, only $18 \%$ of the latter have contact with German people they would call 'acquaintances'.

As for knowledge of the German language, no great discrepancies between the respondents were found, with one exception: the highest number of respondents with a low level of German were from Szczecin. Again, it should be stressed that the assessment of the level of German was subjective and not confirmed by independent evidence. The results are shown in Figure 8.

The questions about the possibility of living in Germany reveal a dichotomy between Szczecin and Wrocław on the one hand and Lublin on the other. Whereas $47 \%$ of respondents from Szczecin and $42 \%$ from Wrocław can imagine living in Germany, only $20 \%$ from Lublin answered this question positively. An overwhelming $80 \%$ of our Lublin respondents cannot imagine living in Germany, but that number decreases if they are asked about studying in Germany (65\%). A rather surprising result is that in answer to the same question, $69 \%$ of the respondents from Szczecin cannot imagine studying in Germany. This might possibly be related to the fact that their perceived language proficiency is low.

Our results also show that almost half (47\%) of the respondents from Wrocław can imagine having a German wife or husband, whereas only $35 \%$ from Lublin and 20\% from Szczecin answered this question positively. Regarding the question about the possibility of having a German passport, an almost identical distribution of answers holds for respondents from Szczecin and Wrocław (31\% would like to have one), while $85 \%$ of respondents from Lublin do not want to have one. The results are illustrated in Figure 9.

The question concerning associations with Germany shows that $82 \%$ of respondents from Lublin associate the country with the war(s), whereas only $47 \%$ of respondents from Wrocław and only 25\% from Szczecin provided this answer. The question eliciting figures associated with Germany had Angela Merkel as the most frequently named by all three groups of respondents, followed by Adolf Hitler and Johann Wolfgang von Goethe. The results are provided in Figure 10. 


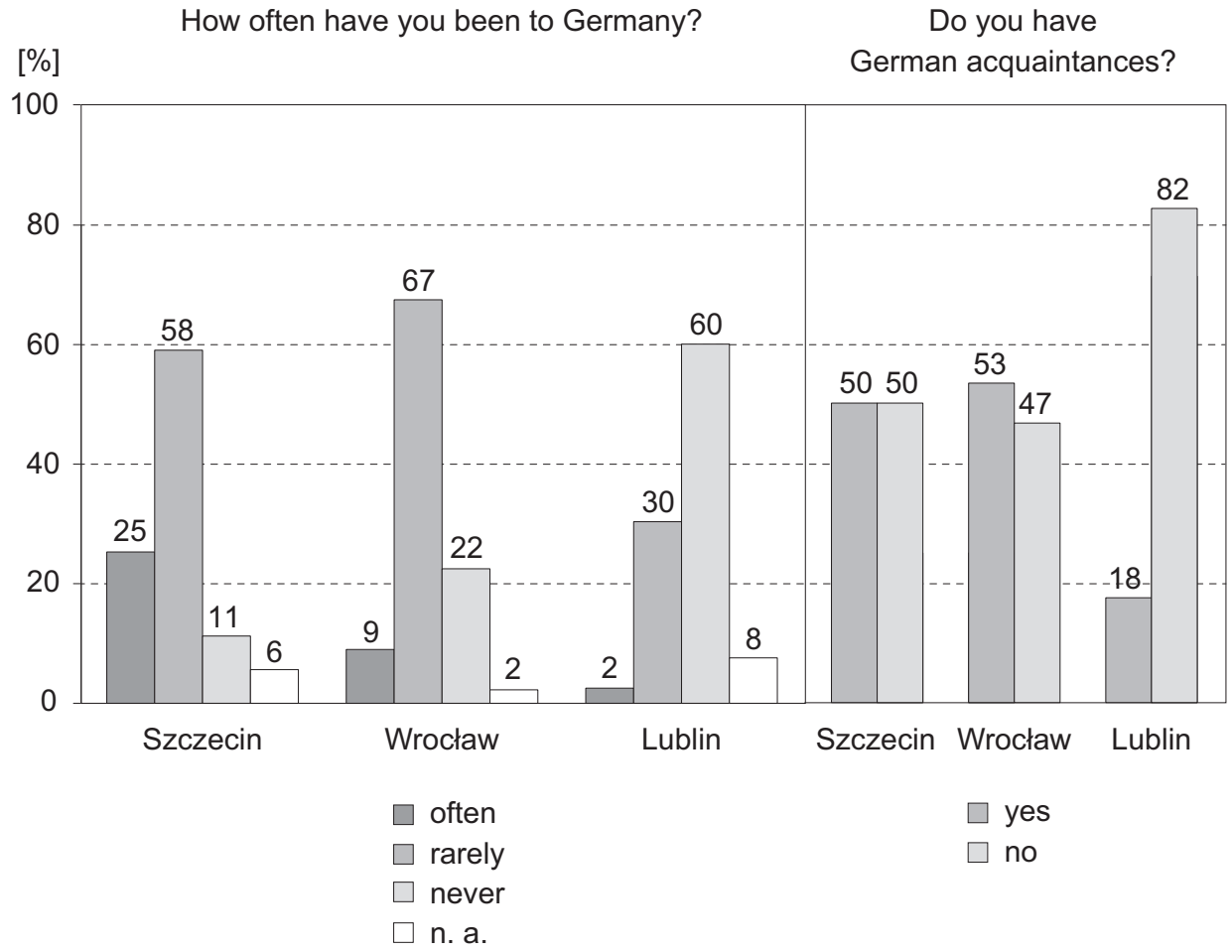

Figure 7: Frequency of contacts (left), German acquaintances (right)

[\%] Do you speak German? What is your level of German?

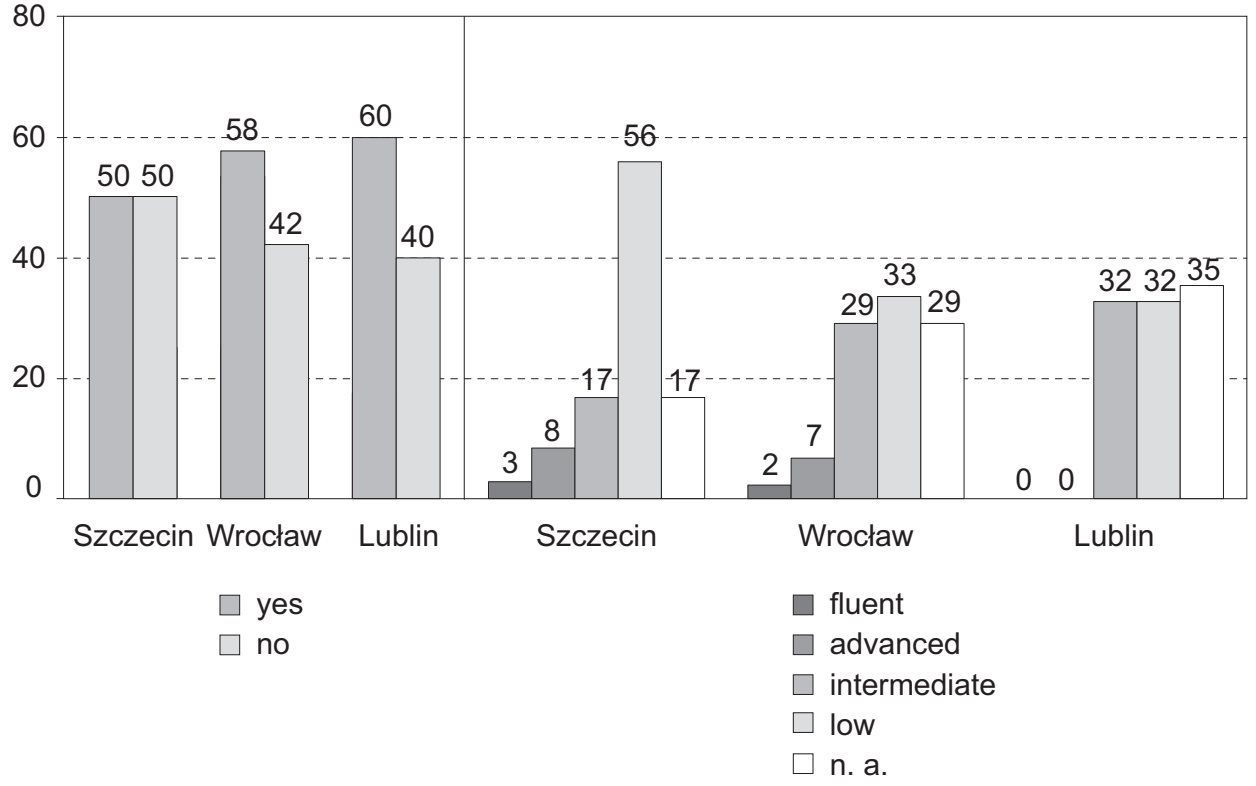

Figure 8: Ability to speak German (left) and proficiency level in German (right) 


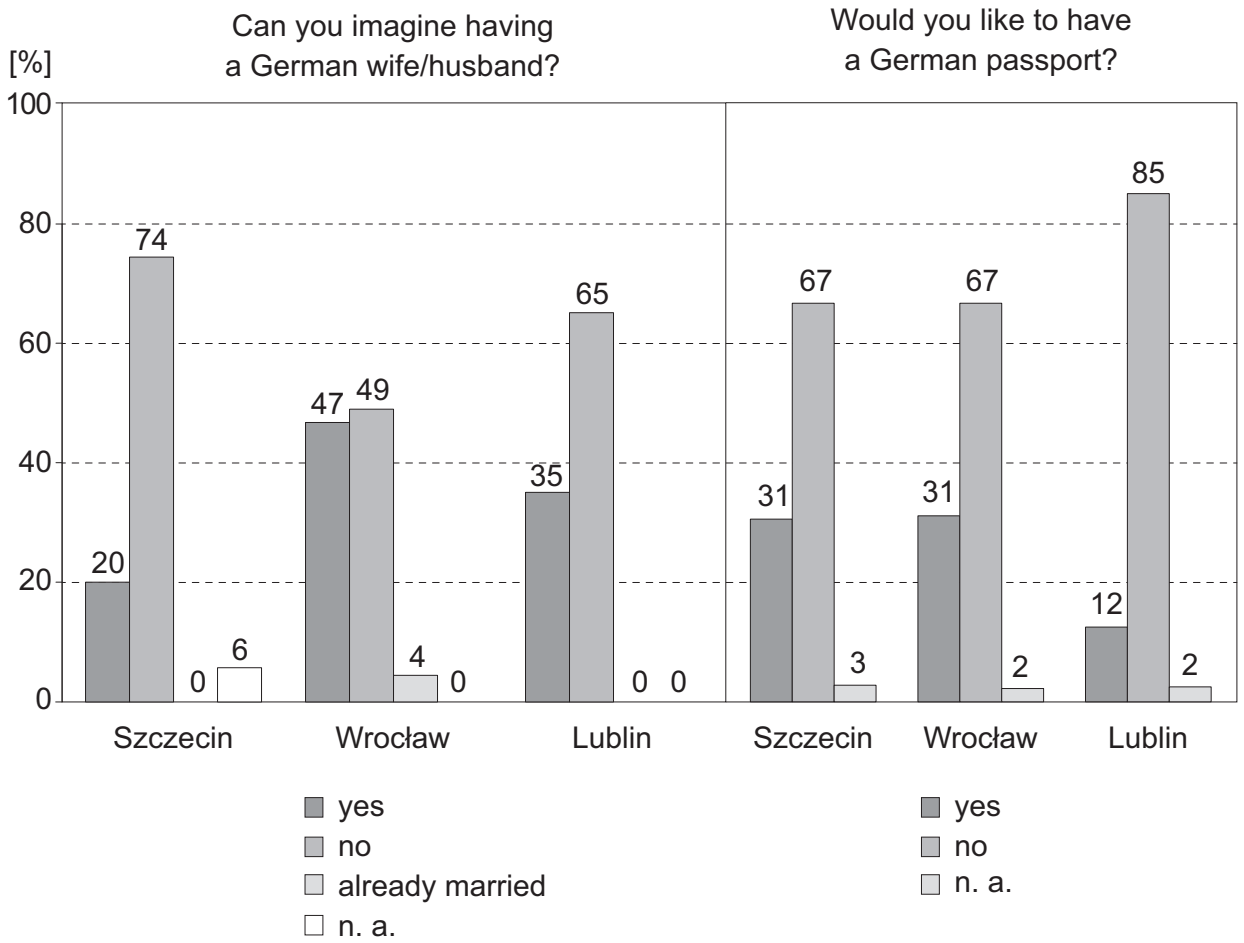

Figure 9: German wife/husband (left) and German passport (right)

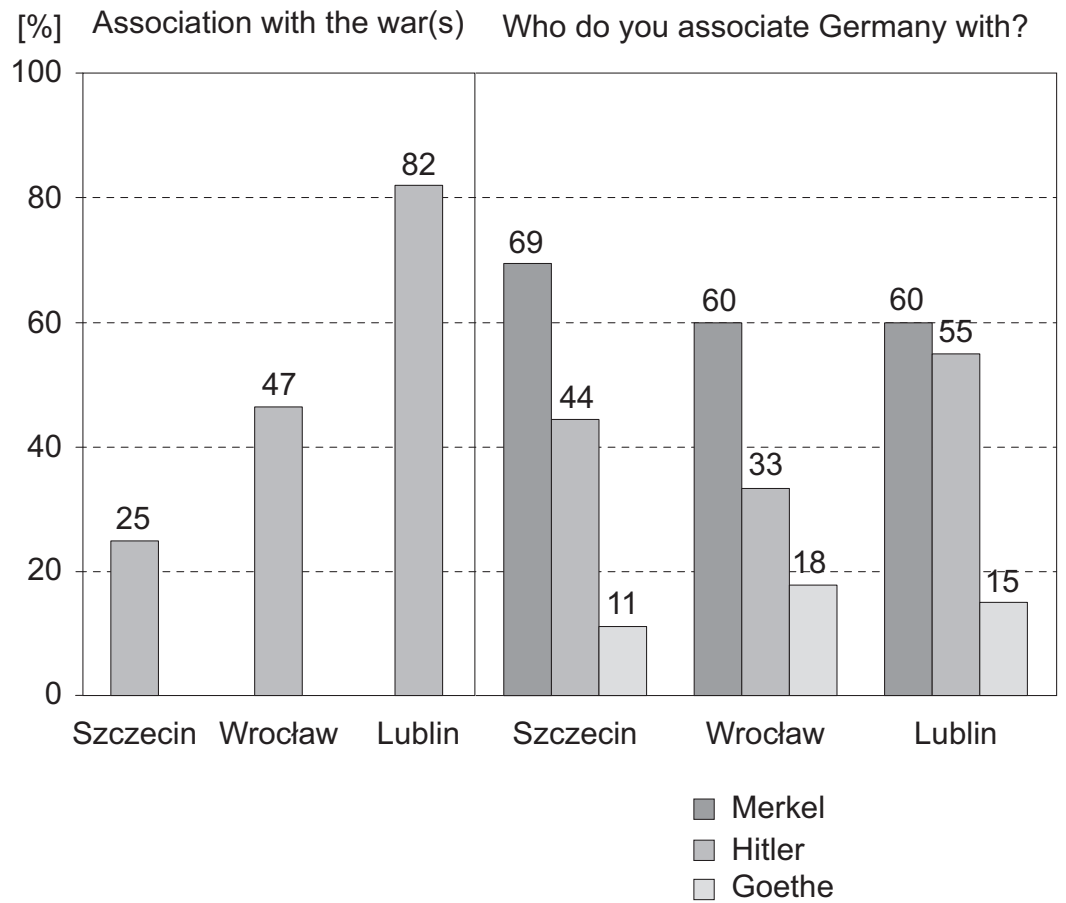

Figure 10: Association with the war(s) (left), association with people (right)

Studia Linguistica 39, 2020

(C) for this edition by CNS 
We conclude that in several aspects there is an essential difference between Szczecin and Wrocław on the one hand and Lublin on the other. Furthermore, the results allow us to draw the conclusion that there is also a difference between respondents from Szczecin and Wrocław to some extent. The latter seem to be more open towards Germans and their culture.

\subsection{Attitudes towards Germany}

Our study shows that attitudes of the study participants (university students) towards German people positively depend on three main factors: the frequency of their contacts with Germans, whether they have German acquaintances and also on their place of residence. Regarding the latter parameter, it turns out that our results vary depending on the Polish city our respondents come from. In particular, in several aspects there is an essential difference between Szczecin and Wrocław on the one hand and Lublin on the other. Moreover, there is also a difference between respondents from Szczecin and Wrocław to some extent, confirming that proximity to the German border does not in itself result in positive attitudes (cf. points raised in Galasinska/Rollo/Meinhof 2002/2018, Krätke 1999). The Wrocław participants in our study turned out to be those with the most positive attitudes towards Germans and their culture. This might be attributed to the fact that Wrocław is the most international city out of those investigated: there is a large community of international students living there, also many international companies are located there, and finally, tourists from Germany account for the largest group of visitors to Wrocław.

In the following we will consider what attitudes Poles have towards Germany and its citizens. To begin with, let us look at things that our respondents particularly like about Germany. Here are some examples of the most frequently named items: the respondents especially appreciate the strong German economy, the good infrastructure (motorways, public transport), reasonable social and environmental policies, and clean cities. But there were also answers such as: beautiful landscapes, German classical music and literature, German football. Among the things they do not like about Germany are, in the first place, the arrogant attitude of some Germans towards the Poles or, more broadly, towards Eastern Europe; and Germans' self-assertion, their "too excessive correctness and officialism" (respondents' own words). Among the things our respondents do not like about Germany, we also find answers such as the lack of humour or German food.

In a related question we asked our respondents to list the three most positive and the three most negative traits associated with Germans. The most frequently cited positive features were accuracy/scrupulousness, reliability and industriousness, and the three most often cited negative features were inflexibility/seriousness, rigorousness, and boastfulness/arrogance. These findings reflect well-known 
stereotypes about Germans which are widely reinforced by the portrayal of Germans in the media, so it is perhaps not surprising to find these ranking at the top of our list. In our study we also asked the participants how they think Poles view Germans. The respondents could freely provide up to five answers, i.e. they could name different traits or issues characterising Germans in the opinion of Poles. They usually provided answers such as: "Poles think that Germans are hard-working, accurate and very correct people", "Poles think that Germans are rich, that they have a well-developed economy, qualitatively very good cars and other products". Next to these positive answers were also more negative answers such as "Poles think that Germans are not really cordial and affectionate", Germans are seen as rather "cold-hearted", keeping other people at a distance, inflexible. There were also strongly negative answers of the sort: "Poles think that all Germans are neo-Nazis, fascists and murderers".

We also asked our respondents the opposite question, namely how they think German people view Poles. As in the previous case, the respondents could freely provide up to five different answers. The most frequently provided answers (rank $1-3$ ) were the following three negative traits ascribed by Germans - not correctly, in the opinion of our respondents - to Poles: drunkenness, thievery and trickery. Also mentioned were laziness and poverty. On the other hand, we also find other, more positive answers and partly the opposite of those just mentioned, for example that Germans think of Poles as hard-working, skilful and well-qualified workers, as very kind, honest and hospitable people.

In sum, young Poles have a rather negative attitude towards Germans and seem to assume that Germans think rather negatively about the Poles. What measures could or should be taken to improve this situation? This was also a question we asked our respondents. The most frequently offered suggestions were: better education, better knowledge of Polish and of German culture and history, frequent meetings, workshops, concerts, sports events organised together with German neighbours, various exchange programmes and also a better media image both of Germans and Poles. Thus we see that educated young Poles stress the need for personal contacts with Germans. Coincidentally, this is also the result of our study. Personal contacts are the best means to really get to know our neighbours and their culture. What is important is therefore also more knowledge about neighbours and their culture. But do the Poles know enough about Germany and Germans? This is a question we also asked our respondents. Only $55 \%$ of the respondents say that they have sufficient knowledge about Germany (based on self-estimation), 15\% admit that they do not know enough about their neighbours, and 30\% cannot really say whether their knowledge about Germany is sufficient or not. ${ }^{3}$

\footnotetext{
${ }^{3}$ It should be noted that in the opinion of our respondents the Germans do not have sufficient knowledge about Poland either.
} 
Another question we asked our respondents was why they would like to know more about Germany. Apart from simple curiosity, they would like to have a better knowledge of Germany as it is their neighbour, with which Poland maintains various relations. Our respondents also point out that a better knowledge can prevent them from thinking in stereotypes, or it can help to overcome prejudices and to break down existing stereotypes of the types revealed above. This is also the best way of fostering mutual understanding. Clearly, with increasing knowledge about neighbours, it is possible to understand them better, to learn to respect their culture, their attitudes towards life, their politics and society. But are Poles and Germans really completely different people? More than half $(55 \%)$ of our respondents think that there is a fundamental difference between Germans and Poles, 30\% do not have an opinion on this issue, and in the opinion of $15 \%$ of the respondents there is no fundamental difference between Germans and Poles.

\section{Cultural similarities and differences between Poles and Germans: Discussion}

Assuming there is a fundamental difference between Germans and Poles, the next question is what this difference could be. Here are some examples of the answers offered by our respondents: Germans and Poles have a different mentality, different cultures and traditions; their economic situation is different - the German economy is better developed; the attitude towards life is different - Poles are more negative, always complaining; Germans are more positive; Germans are often arrogant, whereas Poles often suffer from an inferiority complex; Germans are better organised, conscientious and punctual, while Poles are more canny, though tend to work an angle; Germans often pay too much attention to formalities with no room for improvisation, are "stand-offish" and boring ("stodgy"); by contrast, Poles are more friendly, cordial and affectionate.

Even if more than $50 \%$ of our respondents see radical differences between Germans and Poles, that does not mean there are no common traits. The question "What do Polish and German people have in common?" was answered in the majority of cases as follows: a common history, the European Union, the joint border along the Oder/Odra river, common values, a similar culture, football, similar cuisine; both Germans and Polish like alcohol (beer), sausages, fatty food, etc. The question "Do Polish and German people have some common features?" was answered like this: both Germans and Poles are hard-working and honest, love their families and are patriotic; both are hospitable and love to help others, showing an interest in important issues; Germans and Poles are conservative and do not like change very much. 
In addition, we would also like to briefly comment on other specific differences between Polish culture and German culture. For the purpose of clarity, we will focus on the cultural value dimensions as proposed by Hofstede (1980; see also Kirkman/Lowe/Gibson 2006; for an alternative approach to cultural differences see, e.g. Trompenaars/Hampden-Turner 2011). According to Hofstede, national cultures can be distinguished by the degree to which they share certain cultural values and diverge on cultural dimensions. While this approach is helpful in defining characteristics that might be found in certain national cultures, this can easily lead to overgeneralisations which may be unjustified as it brushes over regional, local and individual identities. However, it is a useful tool to reveal tendencies within specific cultures. Thus, comparing Polish and German culture on these cultural dimensions (see https://www.hofstede-insights.com/country-comparison/germany,poland/), it is striking that both cultures are fairly similar in the extent to which they value individual efforts and a sense of community (individualism score) and the way in which they adhere to male/female roles in society (masculinity score). However, the two cultures differ substantially in the way they view power relations (power distance), in their desire to avoid future uncertainties (uncertainty avoidance) and in how links with the past and traditions are maintained (long-term orientation). A wider discussion of the underlying cultural values of these two cultures is beyond the scope of this paper, but the above discussion serves to show that there are indeed cultural differences present that go beyond the level of language.

\section{Conclusions}

The goal of this study was to shed more light on how young educated Poles (university students) feel about Germany and German people. Based on the previous research we expected the attitudes to be determined by i) the place of living, ii) the level of proficiency in German, iii) the frequency of contact with German people, and iv) personal acquaintances with German people. More precisely, our hypothesis was that more positive attitudes are expected when the respondents live closer to the German border, can speak German better, visit Germany more often, and know more German people personally.

The results of our study show that the place of residence, frequency of contact with German people and number of German acquaintances significantly contribute to attitudes towards Germans. By contrast, proficiency in German turns out not to be significant. In particular, our respondents have more positive attitudes towards German people if they have been to Germany more often and know more German people personally. We also conclude that the place of residence influences the way our respondents feel about Germany and German people. In particular, our study reveals an essential difference between cities closer to the German border, i.e. Szczecin and Wrocław on the one hand, and a city far away 
from Germany, i.e. Lublin, on the other. Furthermore, there is also a difference between respondents from Szczecin and Wrocław to some extent. The latter seem to be more open towards Germans and their culture.

However, one should bear in mind that the results are limited because they are based on a rather small number of respondents (121). In addition, our respondents were recruited from different faculties - economics, electronics, Romance, Slavic and English philology, and journalism - which could also have an impact on our results. As an anonymous reviewer points out, philology students could be more open to other cultures than other students, a point which is worth further research. Finally, we want to emphasise that our study intended to investigate the attitudes of young, educated Poles towards Germany and German people, which means that our investigation is not representative of society as a whole.

To sum up, our study suggests that despite many differences, our respondents notice that Polish and German people share common features. In this very fact lies the key for the future, more precisely for future relations between Germans and Poles. It is important to stress the common properties but also to learn about the differences and to respect them.

\section{References}

AJZEN Icek / FishbeIN Martin, 1980, Understanding Attitudes and Predicting Social behaviour, Englewood Cliffs (NJ).

BAdSTÜBNER Tina / Ecke Peter, 2009, Student expectations, motivations, target language use, and perceived learning progress in a summer study abroad program in Germany, in: Die Unterrichtspraxis/Teaching German 42(1), pp. 41-49.

BLock David, 2014, Second Language Identities, London.

Blommaert Jan, 2006, Language ideology, in: Ricento T. (ed.), Encyclopaedia of Language and Linguistics, Oxford, pp. 510-522.

Bohner Gerd / WänKe Michaela, 2002, Attitudes and Attitude Change, Hove.

Byram Michael, 1997, Teaching and Assessing Intercultural Communicative Competence, Clevedon/Philadelphia/Toronto/Sydney/Johannesburg.

Byram Michael / Golubeva Irina, 2012, Conceptualizing intercultural (communicative) competence and intercultural citizenship, in: Jackson J. (ed.), The Routledge Handbook of Language and Intercultural Communication, London, pp. 85-97.

CBOS 2014, Attitudes to other nationalities. Polish Public Opinion Research Centre. Retrieved from https://www.cbos.pl/EN/publications/reports/2014/020_14.pdf.

CBOS 2017, Attitudes to other nationalities. Polish Public Opinion Research Centre. Retrieved from https://www.cbos.pl/EN/publications/reports/2017/021_17.pdf.

DöRNYEI Zoltán, 2003, Attitudes, orientations, and motivations in language learning: Advances in theory, research, and applications, in: Zoltán D. (ed.), Attitudes, Orientations, and Motivations in Language Learning: Advances in Theory, Research, and Applications, Oxford, pp. 3-32.

DöRNYEI Zoltán, 2014, The Psychology of the Language Learner: Individual Differences in Second Language Acquisition, London.

Galasinska Aleksandra / Rollo Craig / Meinhof Ulrike Hanna, 2002 (2018), Urban space and the construction of identity on the German-Polish border, in: Meinhoff U.H. (ed.), Living (with) Borders: Identity Discourses on East-West Borders in Europe, New York, pp. 131-152. 
Gardner Robert C., 1985, Social Psychology and Second Language Learning: The Role of Attitudes and Motivation, London.

GARDNER Robert C., 2001, Integrative motivation and second language acquisition, in: Zoltán D./ Schmidt R. (eds.), Motivation and Second Language Acquisition, Honolulu, HI: University of Hawaii, Second Language Teaching and Curriculum Center, pp. 1-19.

Gardner Robert C. / Wallace Lambert E., 1972, Attitudes and Motivation in Second-Language Learning, Rowley (MA).

HoFstede Geert, 1980, Culture's Consequences International Differences in Work-Related Values, Beverly Hills (CA).

ISABELli-García Christina, 2006, Study abroad social networks, motivation and attitudes: Implications for second language acquisition, in: DuFon M.A./Churchill E. (eds.), Language Learners in Study Abroad Contexts, Clevendon, pp. 231-258.

Kirkman Bradley L. / Lowe Kevin B. / Gibson Cristina B., 2006, A quarter century of culture's consequences: A review of empirical research incorporating Hofstede's cultural values framework, in: Journal of International Business Studies 37(3), pp. 285-320.

Komisja Europejska / EACEA / Eurydice, 2016, Key Data on Teaching Languages at School in Europe - 2017 Edition. (Kluczowe dane o nauczaniu języków w szkołach w Europie - 2017) Raport Eurydice. Luxemburg: Publications Office of the European Union.

KRÄTKE Stefan, 1999, Regional integration or fragmentation? The German-Polish border region in a new Europe, in: Regional Studies 33(7), pp. 631-641.

MASGOREt Anne-Marie / GARDNer Robert C., 2003, Attitudes, motivation, and second language learning: a meta-analysis of studies conducted by Gardner and associates, in: Language Learning 53(1), pp. 123-163.

MiнUŁKa Krystyna, 2007, Wie entstehen Vorurteile?, in: Lublin Studies in Modern Languages and Literature 31(1), pp. 175-192.

MinuŁKa Krystyna, 2008, Der Oder-Neiße-Komplex-eine symbolische Grenze in den DeutschPolnischen Beziehungen, in: Lublin Studies in Modern Languages and Literature 32(1), pp. 301-313.

MiLroy Lesley, 1987, Language and Social Networks. 2nd edition, Oxford.

R Development Core Team 2013, A Language and Environment for Statistical Computing (version 3.0.2). R Foundation for Statistical Computing, Vienna. Retrieved from http://www.R-project. org/.

RAdomski Marek / SzPYra-KozŁowsKa Jolanta, 2014, A pilot study on Poles' attitudes to foreignaccented Polish and its users, in: Studies in Polish Linguistics 9, pp. 67-87.

Risager Karen, 2006, Language and Culture: Global Flows and Local Complexity, Buffalo.

Statistisches Bundesamt, 2019, Bevölkerung: Deutschland, Stichtag, Geschlecht, Altersgruppen, Staatsangehörigkeit. Retrieved from https:/www.destatis.de/DE/ZahlenFakten/Gesellschaft Staat/ Bevoelkerung/Bevoelkerungsstand/Bevoelkerungsstand.html

TrompenaARs Fons / HAMPDEN-TuRner Charles, 2011, Riding the Waves of Culture: Understanding Diversity in Global Business. Nicholas Brealey International.

WiLLIAMs Tracy Rundstrom, 2005, Exploring the impact of study abroad on students' intercultural communication skills: Adaptability and sensitivity, in: Journal of Studies in International Education 9(4), pp. 356-371.

ZAPPETTINI Franco, 2019, European Identities in Discourse: A Transnational Citizens' Perspective, London. 


\section{Questionnaire}

Please indicate the right answer. Please be honest. :)

1. Year of birth

2. Sex

$$
\text { male female }
$$

3. Place of birth (city/village, country).

4. How would you characterise your contact with Germans?

I have very frequent contact (at least once a week)

at least once a year

every five years

I have never had any contact with Germans

Here you can add additional information if you would like to make your answer more precise:

5. Where are your parents from?

$\begin{array}{lccc}\text { mother: } & \square & \square & \square \\ & \text { Polish } & \text { German } & \text { other } \\ \text { father } & \square & \square & \square \\ & \text { Polish } & \text { German } & \text { other }\end{array}$

6. Do you have German relatives?

7. Do you have German acquaintances?

yes no

8. Do you have German friends?

yes no

9. Have you ever visited Germany?

yes no 
10. If so, how often do you visit Germany?

$$
\begin{aligned}
& \text { often } \\
& \text { rarely } \\
& \text { never }
\end{aligned}
$$

11. What is the purpose of your visits to Germany? (Please choose the right answer/s!)

$$
\begin{aligned}
& \text { family visits } \\
& \text { longer holiday stays } \\
& \text { short weekend visits } \\
& \text { holidays (Christmas, Easter etc.) } \\
& \text { shopping } \\
& \text { other reasons }
\end{aligned}
$$

12. Can you speak German?

yes

no

13. If so, how would you assess your level of German?

14. Do you like the German language?

$$
\begin{aligned}
& \text { fluent } \\
& \text { advanced } \\
& \text { intermediate } \\
& \text { beginner }
\end{aligned}
$$

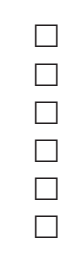

14. Do you like the German language?

$\begin{array}{ll}\square & \square \\ \text { yes } & \text { no }\end{array}$

15. If you can't speak German, would you like to learn it?

$\begin{array}{ll}\square & \square \\ \text { yes } & \text { no }\end{array}$

16. Do you like Germans?

yes now difficult to say

17. Do you admire Germans?

yes no

18. If so, what do you admire them for? 
19. What do you associate Germans with? Please name the 5 most important character traits/features of national life:

1.

2.

3.

4.

5 .

Additional remarks:

20. Please name three positive characteristics of Germans:

1.

2.

3.

21. Please name three negative characteristics of Germans:

1.

2.

3.

22. Please name three positive characteristics of Polish people:

1.

2.

3.

23. Please name three negative characteristics of Polish people:

1.

2.

3.

24. In your opinion, is there a fundamental difference between Polish and German people?

yes no I do not know

25. If so, what is this difference?

26. What is common to Germans and Poles? What are their common properties? Please name three such properties:

1.

2.

3. 
27. What do you think Germans think about Poles? Please name 5 character traits/features of national life and indicate in each case whether you agree with it:

1.

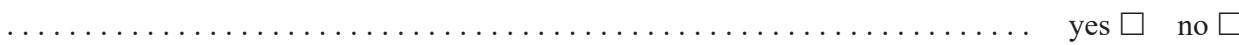

2 .

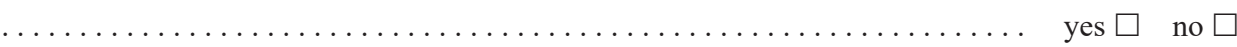

3.

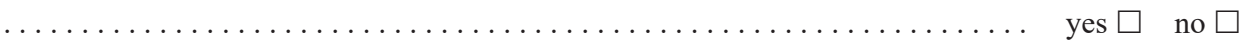

4.

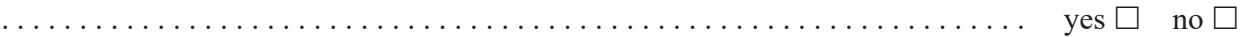

5 . yes $\square$ no $\square$

28. What do you think Poles think about Germans? Please name 5 character traits/features of national life and indicate in each case whether you agree with it.

1.

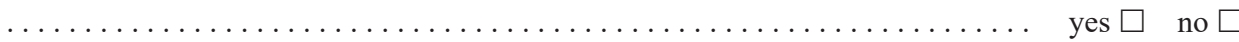

2

3.

4.

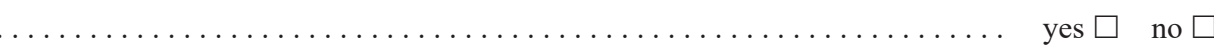

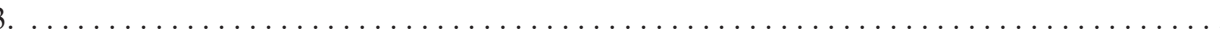
yes $\square$ no $\square$

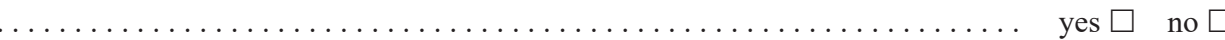
5 . yes $\square$ no

29. If you think that Poles have negative attitudes towards Germans, how could this be changed?

30. Could you imagine studying in Germany?

yes no

31. Could you imagine living permanently in Germany?

yes no

32. Could you imagine working for a German company in Poland?

yes no


33. Could you imagine having a German boss?

yes no

34. Would you prefer to have a Polish or a German boss (in Poland)?
a Polish boss
$\square$ yes
$\square$ no
a German boss
$\square$ yes
$\square$ no

35. Could you imagine working in Germany?

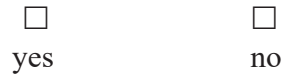

36. Could you imagine marrying a German person?

yes no

37. What do you like most about Poland?

38. What do you like most about Germany?

39. What do you not like about Poland?

40. What do you not like about Germany?

41. Do you think that Germans know enough about Poland?

yes no don't know

42. Would you like Germans to know more about Poland?

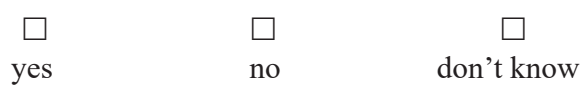


43. If so, what should they know?

44. Do you yourself know enough about Germany?

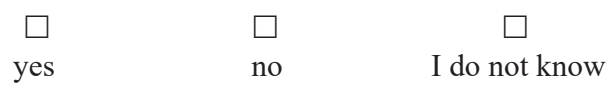

45. Would you like to know more about Germany?

yes

no I do not know

46. If so, why would you like to know more about Germany?

47. Do you know any German personalities (from the present or from history)?

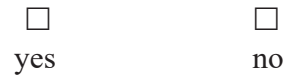

48. If you know some, please write their names:

1.

2.

3.

49. Do you know any Polish personalities (from the present or from history)?

yes no

50. Please write some names:

1.

2.

3.

51. Would you like to have a German passport (German citizenship)?

tak nie

52. Please provide the reason for your answer:

THANK YOU! :)

Studia Linguistica 39, 2020

(C) for this edition by CNS 


\section{What influences our attitudes? A survey study on attitudes of Polish university students towards German people}

This study reports the results of a survey conducted on 121 Polish students at three universities in Szczecin, Wrocław and Lublin. The goal was to examine what young Poles think about Germany and Germans, and to what extent their attitudes towards German people are influenced by factors such as where they live, their level of German, the frequency of contact they have with Germans, and their acquaintances with them. The analysis reveals that while proficiency in German is not significant, other parameters such as frequency of contact or where they live contribute to forming their attitudes.

Keywords: stereotypes, attitudes, questionnaire study, German, Polish. 